\title{
Editorial
}

\section{The nursing discipline in the post-pandemic era}

\author{
Esther Cabrera \\ Universitat Pompeu Fabra, Tecnocampus, Chronic Care and Health Innovation Research Group (GRACIS), Barcelona, Spain
}

It is clear that the COVID-19 pandemic has impacted our health systems and shaken our societies. In Europe, citizens have experienced tragic circumstances that have changed their lifestyles and relationships with colleagues, friends, and family.

The pandemic has also had a lasting adverse impact on health and care workers, including nurses and midwives who account for nearly $50 \%$ of the global health workforce. Pre-existing health workforce issues in many countries, such as staff and skills shortages, have been exacerbated by putting the health, well-being, lives, and safety of nurses and midwives, particularly those providing front-line services, at risk. The ongoing high demands on these workers have further deepened the worries about the already existing challenges in the labor force. The nursing workforce is under immense pressure - nurses are experiencing heavy workloads, insufficient resources, unsafe working conditions, high rates of COVID-19 infection, burnout, and stress. These circumstances have been expressed by the International Council of Nurses (ICN) as the "COVID-19 Effect" (ICN, 2021).

Before the pandemic, global data indicated a shortage of at least six million nurses. ICN's own research suggests a further four million nurses will retire over the next decade, and the cumulative influence of the mass-traumatization caused by the "COVID-19-effect" could see a further two or three million nurses leaving the profession.

Over the past year, the "Nursing Now" campaign has played an important role in trying to shed light on the nursing and midwifery situation around world. The message is clear: countries must implement policy urgently, with the aim of developing an action-orientated strategy on improving circumstances for nurses. Governments must take drastic action to invest in nursing education, jobs, leadership, and service delivery, to safeguard the delivery of care in their future healthcare systems. They must strengthen the role of nurses in the health, social and education systems (https://www.nursingnow.org/).

Faced with the current scenario, health professionals and nurses must build and show their resilience, and find the opportunity to demonstrate their leadership and competencies in interdisciplinary healthcare. We have learned from this pan- demic that the nurse workforce is a crucial asset to any health care system.

The diversification of professional nursing roles has proven to be an adequate solution to improve healthcare outcomes. Innovative Advance Practice Nursing (APN) roles are relevant for transforming the model of care towards a high specialization and interdisciplinary delivery of public health (Beauchesne et al., 2020). APNs contribute to identifying the need for health care services, workforce planning, public demands for improved access, professional development/career advancement, and optimization of healthcare resources (Cabrera and Zabalegui, 2020). Healthcare integration, care coordination, improvement of services access, and focus on sustainability of health care also contribute to better health outcomes. APN's can autonomously assume practice and take part in the effective transition of care in which they play a role. APNs can also place an emphasis on leadership and continuous research to contribute to the development of strategic policies and services (Sevilla Guerra et al., 2021).

The level of expertise and postgraduate education (master and doctoral degrees) of APNs increases significantly nurses' competencies. At the same time, the global pandemic has shown an increased demand for digital, competency-based education, to provide all nurses with sufficient access to evidence, quality education and learning. Academic institutions must deliver competency-based clinical and professional development programs and promote the development of research capacity. This includes partnerships with healthcare providers for evidence-based approaches in hospitals, and primary health care centers.

The International Council of Nurses (ICN) represents nurses worldwide, working to ensure quality of nursing care and to generate sound global health and nursing policies. Policymaking consists of finding best practices and providing information to contribute to a universal and common understanding. With this in mind, the ICN has supported the development of advanced practice nursing. They established the definition of the advanced practice nurse (APN) in 2002, the Scope of Practice for APNs, and Standards and Competencies of the APN (ICN, 2020).

\footnotetext{
* Corresponding author: Esther Cabrera, Universitat Pompeu Fabra, Tecnocampus, Chronic Care and Health Innovation Research Group (GRACIS), Ernest Lluch 32, 08032 Mataró, Barcelona, Spain; e-mail: ecabrera@tecnocampus.cat http://doi.org/10.32725/kont.2021.052 
The participation of nurses is vital in health care decision-making and its political dialogue. Nurse leaders are prepared to contribute in solving healthcare challenges. Moreover, nurses are the largest group of health professionals, have the greatest reach, and are among the most trusted professionals in the health system. A political decision to invest in the future development of nursing brings improvements in population health, health equity, social inclusion, gender equality and economic growth.

In May 2021, the ICN, on behalf of the over 27 million nurses worldwide, published the report "Strengthening nursing and midwifery: investments in education, jobs, leadership and service delivery". As a result, the WHO has recently presented the Global Strategic Directions for Nursing and Midwifery 2021-2025 (WHO, 2021). This document encompasses the four areas of priority: education, jobs, leadership, and service delivery. Each "strategic direction" comprises two to four prioritized policy actions needed to achieve it.

- Education strategic direction: midwife and nurse graduates match or surpass health system demand, and have the requisite knowledge, competencies, and attitudes to meet national health priorities.

- Job strategic direction: increasing availability of health workers by sustainably creating nursing and midwifery jobs, effectively recruiting, and retaining midwives and nurses, and ethically managing international mobility and migration.

- Leadership strategic direction: increase the proportion and authority of midwives and nurses in senior health and academic positions, and continually develop and empower the next generation of nursing and midwifery leaders.

- Service delivery strategic direction: midwives and nurses work to the full extent of their education and training in safe and supportive service delivery environments.
It ought to be obvious that countries which invest in nursing education and the workforce, will benefit from a resilient healthcare system which, in return, will have a positive long-term impact on citizens' health. Considering the lessons learned from the pandemic, and sharing these experiences, should lead to building a health system with a strong nursing workforce - resulting in better health for all.

\section{References}

1. Beauchesne MA, Honig J, Sevilla S, Carryer J, Debout C, Ganz FD, et al. (2020). A snapshot of clinical educational experiences for advanced practice nurses worldwide. Nurse Pract 45(9): 14-22. DOI: 10.1097/01.NPR.0000694700.16463. c7.

2. Cabrera E, Zabalegui A (2020). Nurses' workforce and competencies. A challenge for health systems more than ever. Nurse Educ Pract 48: 102858. DOI: $10.1016 / j$. nepr.2020.102858.

3. International Council of Nurses (ICN) (2020). Guidelines on advanced practice nursing. [online] [cit. 2021-11-30]. Available at: https://www.icn.ch/system/files/documents/2020-04/ ICN_APN\%20Report_EN_WEB.pdf

4. International Council of Nurses (ICN) (2021). International council of nurses COVID-19 update. [online] [cit. 2021-11-30]. Available at: https://www.icn.ch/sites/default/files/inline-files/ ICN\%20COVID19\%20update\%20report\%20FINAL.pdf

5. Sevilla Guerra S, Zabalegui A, Comellas Oliva M, Estrem Cuesta M, Martín-Baranera M, Ferrús Estopà L (2021). Advanced practice nurses: Analysis of their role from a multicentre cross-sectional study. Int Nurs Rev 1-8. DOI: 10.1111/inr.12706.

6. WHO - World Health Organization (2021). Global strategic directions for nursing and midwifery 2021-2025. [online] [cit. 2021-11-30]. Available at: https://apps.who.int/iris/ handle/10665/344562 